\title{
Evaluation of speed-accuracy trade-off in a computer task in individuals with cerebral palsy: a cross-sectional study
}

Deborah Cristina Gonçalves Luiz Fernani ${ }^{1,2^{*}}$, Maria Tereza Artero Prado ${ }^{1,2}$, Talita Dias da Silva ${ }^{3}$, Thais Massetti ${ }^{4}$, Luiz Carlos de Abreu ${ }^{2}$, Fernando Henrique Magalhães ${ }^{3}$, Helen Dawes ${ }^{5,6}$ and Carlos Bandeira de Mello Monteiro 2,3,4

\begin{abstract}
Background: Individuals with Cerebral Palsy (CP) present with sensorimotor dysfunction which make the control and execution of movements difficult. This study aimed to verify the speed-accuracy trade-off in individuals with CP.

Methods: Forty eight individuals with CP and 48 with typical development (TD) were evaluated (32 females and 64 males with a mean age of $15.02 \pm 6.37$ years: minimum 7 and maximum 30 years). Participants performed the "Fitts' Reciprocal Aiming Task v.1.0 (Horizontal)" on a computer with different sizes and distance targets, composed by progressive indices of difficulty (IDs): ID2, ID4a and ID4b.

Results: There were no statistical differences between the groups in relation to the slope of the curve (b1) and dispersion of the movement time $\left(r^{2}\right)$. However, the intercept (bo) values presented significant differences $(F(1.95)=11.3 ; p=.001])$, with greater movement time in the CP group compared to the TD group. It means that for individuals with $C P$, regardless of index difficulty, found the task more difficult than for TD participants. Considering CP and TD groups, speed-accuracy trade-off was found when using different indices of difficulty (ID2 and ID4). However, when the same index of difficulty was used with a larger target and longer distance (ID4a) or with a narrow target and shorter distance (ID4b), only individuals with CP had more difficulty performing the tasks involving smaller targets. Marginally significant inverse correlations were identified between the values of b1 and age $(r=-0$. $119, p=.052)$ and between $r^{2}$ and Gross Motor Function Classification System $(r=-0.280, p=.054)$, which did not occur with the Manual Ability Classification System.
\end{abstract}

Conclusion: We conclude that the individuals with CP presented greater difficulty when the target was smaller and demanded more accuracy, and less difficulty when the task demanded speed. It is suggested that treatments should target tasks with accuracy demands, that could help in daily life tasks, since it is an element that is generally not considered by professionals during therapy.

Trial registration: ClinicalTrials.gov, NCT03002285, retrospectively registered on 20 Dec 2016.

Keywords: Cerebral palsy, Motor activity, Disabled people, Motor skills

\footnotetext{
* Correspondence: deborah@unoeste.br

'University of West Paulista, Presidente Prudente, SP, Brazil

¿2aboratory Design and Scientific Writing Department of Basic Sciences, ABC

Faculty of Medicine, Av. Príncipe de Gales, 821, Vila Principe de Gales, Santo

André, SP 09060-650, Brazil

Full list of author information is available at the end of the article
} 


\section{Background}

Cerebral palsy (CP) is a common cause of motor dysfunction that affects children and adults [1], defined as a non-progressive disorder in the brain that occurs during the fetal period or early childhood $[2,3]$. The motor alterations in these individuals yield varying degrees of involvement of the upper limbs [4], impairing functionality and hindering the control and execution of movements [5-8]. Due to these difficulties in motor control, several motor limitations in the upper limbs, such as longer movement durations, reduced trajectory straightness and lower peak velocities, are observed to affect daily activities and participation in several occupational tasks throughout life [9-11].

When considering optimal training programs for individuals with $\mathrm{CP}$, a number of exercise interventions have been considered to be effective including: endurance, strength, speed and power interventions [12-15]. However, there is limited evidence to support the effectiveness of these training approaches for improving mobility and function.

A recent review suggests that speed rather than strength training might be effective in improving functional mobility of CP individuals [13]. However, there is limited understanding as to the relationship between speed and accuracy in individuals with CP. The speed accuracy relationship is particularly important when considering upper limb functional tasks as compared to functional mobility. In typically developed (TD) individuals, movement speed and accuracy, and their relationship, is inversely proportional except when the need for accuracy and speed coexists whereby both can be achieved [16]. For a movement to be performed accurately, muscle coordination and co-contraction need to occur $[17,18]$. When a movement is performed quickly, generally a speed modulation strategy is used, whereby muscle co-contraction is reduced with a subsequent reduction in accuracy [16-18].

The mechanisms underlying the speed-accuracy tradeoff are more complex than previously thought, with individuals being able to utilize a speed-energy-accuracy trade-off for goal-directed movements; whereby individuals can move faster while preserving movement accuracy by using a strategy where muscles are co-contracted around the joint but at a high energetic cost [16]. As such, a speed modulation strategy is preferred to a cocontraction strategy for faster movements, and a strategy to preserve energy economy typically prevents us from executing faster accurate movements [16].

Considering individuals with $\mathrm{CP}$, changing the distance of a movement may be less taxing, as this can be controlled through a simpler model of agonist and antagonist muscle activity as compared to that required for more accurate movements [19-21]. However, Imms et al. [22] states that spasticity is the most common motor disorder in CP, characterized by a velocitydependent increase in the tonic stretch reflex which leads to slow and effortful movement. Meskers [23] also pointed out that individuals with movement disorders caused by neurological diseases, such as CP, due to impaired muscle control have atypical force generation and inappropriate tension regulation affecting the normal movement velocity profile, which is essential to obtain fast movements, thus this characteristic could make tasks that demand speed more challenging for people with CP.

Regarding the conflicting evidence about the influence of speed or accuracy demand during a task in individuals with CP, the assessment and investigation of the speedaccuracy trade-off is essential in order to develop optimal exercise interventions that consider the speed at which movements should be performed when trying to facilitate accuracy and the components of a task (distance, size of the target). Task manipulation may for instance increase difficulty and require individuals with $\mathrm{CP}$ to move slower and with greater neuromuscular cost. Perhaps more importantly a better understanding will inform the design of systems and devices for individuals with $\mathrm{CP}$, such as modification of computer switch systems to integrate considerations of distance and target accuracy in order to improve and ease engagement in occupational tasks.

In order to better understand the relationships between distance and accuracy, participants were engaged in a movement time task with different indices of difficulty (IDs). The same ID was performed in two ways (considering the relation between widths and distances), where tasks were performed with thicker sidebars and longer distances between them and thinner sidebars with shorter distances, in order to evaluate if the size of the target (accuracy demand) has more influence in the performance than the distance between them (speed demand).

Given this, this study aimed to verify the speedaccuracy trade-off in individuals with CP. We hypothesize that there should be an inverse relationship between task difficulty and performance (measured by means of movement time) for both TD and $\mathrm{CP}$ individuals, whereby the $\mathrm{CP}$ individuals should be generally slower than the TD controls and this effect would be more pronounced during movements with higher levels of difficulty. We further hypothesized that the greater the severity of $\mathrm{CP}$, the greater should be the impairment in performance, but with no differences between tasks with same index of difficulty, i.e. tasks that demand more accuracy (size of target) or speed (distance between targets). 


\section{Methods}

\section{Study design}

An observational study that analyzed the motor control system by evaluating the performance in a computer task in individuals with $\mathrm{CP}$ and in a control group of typically developed individuals.

\section{Participants}

In total, 96 individuals were evaluated, being 48 individuals with CP and 48 with typical development (TD), matched by age and sex. The sample was composed of 32 females and 64 males with a mean age of $15.02 \pm 6.37$ years (minimum 7 and maximum 30 years) The participants of the CP group comprised 25 individuals with hemiparesis, 19 with diparesis and 4 with quadriparesis. A previous statistical analysis was made to find out differences between type of $\mathrm{CP}$, considering the indices of difficulty as dependent variables, with no difference found $(p>0.05)$. Thus, we include all participants in the study, wherein all individuals in the CP group showed to be able to perform the task.

In the Gross Motor Function Classification System (GMFCS) [24], 29 individuals were classified with level I, 6 with level II, 6 with level III and 7 with level IV. According to the Manual Ability Classification System (MACS) [25], 34 individuals obtained level I, 9 level II and 5 level III.

The inclusion criteria were a medical diagnosis of $\mathrm{CP}$, of levels I to IV according to the GMFCS, a classification system that ranks individuals with $\mathrm{CP}$ from I to $\mathrm{V}$, in which children in Level I present some difficulty with speed, balance, and coordination, but with ability to perform all the activities of their age-matched peers, while children in level $\mathrm{V}$ present difficulty in achieving any voluntary control of movement and controlling their head and trunk posture in most positions [26]. For the inclusion criteria, they should also be between levels I to III according to MACS, that similarly to GMFCS, but considers upper limb function specifically and consists of five levels, where level I represent the highest functional level and level $\mathrm{V}$ the lowest functional level [25]. These classification were made by two professionals specialized in CP. The last inclusion criterion was previous use of mouse in their computational activities.

The exclusion criteria were the presence of surgery or a chemical neuromuscular blockade in the upper limbs within 6 months prior to participation in the study and disorders in cognitive function that would prohibit comprehension of the experimental instructions. The comprehension ability was determined through two trials to perform the task, with lack of comprehension being determined on individuals not attempting to follow instructions and perform the task.

\section{Material}

The software used in this study was "Fitts' Reciprocal Aiming Task v.1.0 (Horizontal)" developed by Okazaki [27], in the public domain and available on the Internet, which was performed on a Toshiba notebook ${ }^{\bullet}$, model Satellite A60-S1561, Fortrek ${ }^{\oplus}$ OM-302.

This instrument is used to verify motor control through analysis of the speed and accuracy of movement, which is determined through the log-linear relation between target size and task distance between them using a mathematical equation, and analyzed by Fitts' law, which describes the relation between movement accuracy and speed [28], resulting in the difficulty index. And, the more difficult the task, this will require greater movement time for execution [29]. Thus, the ID2 was composed by target sidebars thicker $(3 \mathrm{~cm})$, with little distance between them $(6 \mathrm{~cm})-(\log 2[(2 \times 6) / 3]=\log 24=2)$, the ID4a had thicker sidebars $(3 \mathrm{~cm})$ with a greater distance between them $(24 \mathrm{~cm})-(\log 2[(2 \times 24) / 3]=\log 216=4)$, and the ID4b had thinner target sidebars than used in ID4a $(1.5 \mathrm{~cm})$, however, the with less distance between them $(12 \mathrm{~cm})-(\log 2[(2 \times 12) / 1.5]=\log 216=4)[30,31]$.

The task was composed of targets of different sizes, being that the smaller targets require more time to execute due to the necessity of increased accuracy [32, 33] and, if the distance between targets reduces, the speed of movement becomes greater and the accuracy decreases.

Therefore, to evaluate the trade-off between speed and accuracy, two different indices of difficulty were used (ID2 and ID4). The difficulty level was increased by changing the width and distance between the bars (Fig. 1). In addition, to evaluate if the size of the target (accuracy demand) requires more movement time when compared to the distance between them (speed demand), ID4 was used in two different ways (ID4a and ID4b), for which the distance between the bars and the width were different, but the ID was maintained. As the ID was maintained, should not exist difference in movement time between ID4a and ID4b.

\section{Procedure}

The experiment was composed of three trials at each of the indices of difficulty: ID2, ID4a and ID4b. The participants performed the tasks individually in a room, with only the evaluator present, seated on a chair (or their own wheelchair), which was adjusted in height according to the needs of the individual. A footrest was available, when necessary. The computer was placed on a table, and each participant was given instructions and presented with the task, in which the individual, after hearing an alarm from the computer, was required to click alternately and intermittently with an external mouse cursor on two parallel bars with three sizes of target and three distances which were used to determine different 


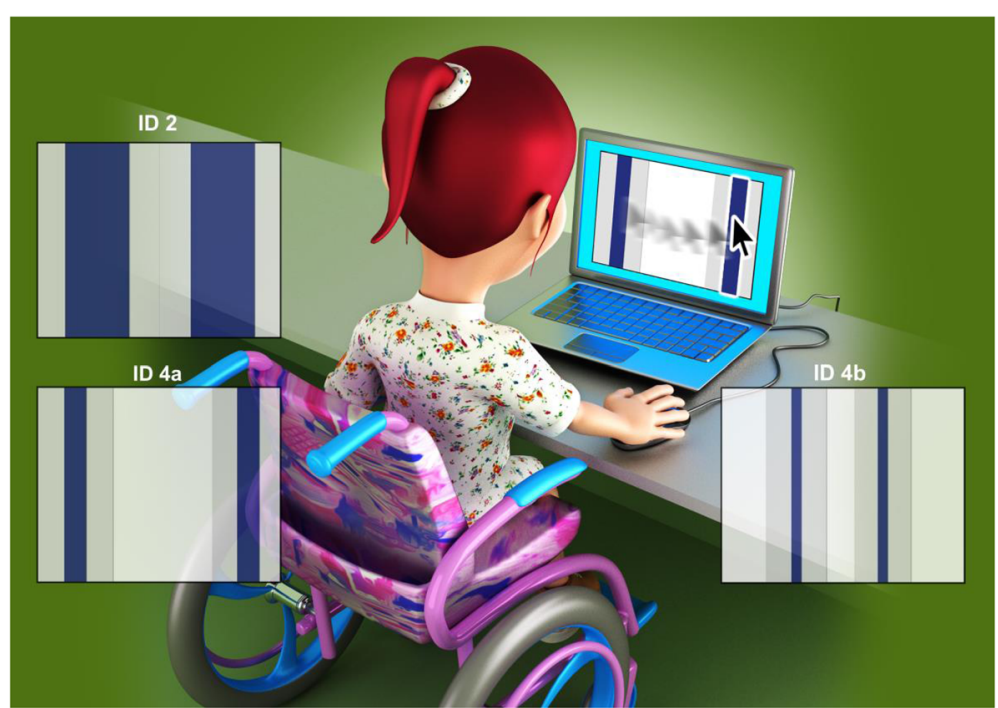

Fig. 1 Individual in a wheelchair* performing the task interfaces at different indices of difficulty ${ }^{*}$ some individuals in this study were seated on a regular chair. Source: figure created by the authors

indices of difficulty, and arranged vertically. The instructions given were 'on hearing the alarm click with the greatest speed and accuracy possible, for a period of 10 seconds, until you hear a second alarm which indicates the end of your attempt'.

Directly following the attempt, the total movement time was registered by software, dividing the seconds obtained in each attempt by the number of "clicks" on targets. If more than two clicks were wrong, the individual repeated the task.

We did not assess or give instructions about the pattern of movement, so they could perform the task in the easier way for each one, i.e. movement of the upper limb in general (hand, wrist, elbow, and shoulder).

\section{Statistical analysis}

Regarding the comparisons for movement time on each index of difficulty, an ANOVA with factor 2 (groups: Cerebral Palsy - CP, Typical Development - TD) by 3 (index of difficulty - ID: ID2, ID4a, ID4b) was conducted, with repeated measures for the factor index of difficulty. Post hoc test was carried out using Tukey-HSD $(p<.05)$.

In order to establish whether the groups responded to the relation between accuracy and speed, a linear regression analysis was performed on the movement time data, using the curve estimation and obtaining the values of: b0 (intercept), b1 (slope of the curve) and $\mathrm{r}^{2}$ (movement time dispersion) of each participant; every attempt at the indices of difficulty being considered. MANOVA One way was used to compare the means of the groups in the three variables of interest (b0, b1 and $\mathrm{r}^{2}$ ).

A multiple linear regression analysis considering increase in movement time ( $\Delta$ between $4 \mathrm{a}$ and 2 ; and between $4 \mathrm{~b}$ and $4 \mathrm{a}$ ) was performed to determine which factors (age, gender, Gross Motor Function Classification System - GMFCS, Manual Ability Classification System MACS) influenced the increase in movement time.

To verify associations between GMFCS, MACS, age, b0, b1 and $r^{2}$, the Pearson correlation coefficient was used. The software package used was SPSS, 20.0.

\section{Results}

In this study it was verified that the $\mathrm{CP}$ group used longer movement time to complete the task than TD group. An inverse relationship was observed between speed and accuracy of movement in individuals with TD, but not in those with CP.

The ANOVA with factors groups (CP and TD) and index of difficult (ID2, ID4a, ID4b), with repeated measures for the factor ID was performed to explore the effects of index of difficult on the movement time, determined in items below.

\section{ID2 - ID4a}

There was a statistically significant difference between the indices of difficult $\left[\mathrm{F}(1.94)=69.3 ; p<.001 ; \mathrm{n}^{2}=0.42\right]$. This result demonstrates that the movement time increased significantly from ID2 (mean $=1019 \pm 60 \mathrm{~ms}$ ) to ID4a $($ mean $=1449 \pm 60 \mathrm{~ms})$. However, no interaction was found between Groups and indices of difficult.

In addition, an effect for groups [F1.94) = 33.9; $p<0.001 ; \mathrm{n}^{2}=0.27$ ] was found, in which the individuals with CP (mean $=1575 \pm 80 \mathrm{~ms}$ ) were $682 \mathrm{~ms}$ slower than those in the TD group (mean $=893 \pm 80 \mathrm{~ms}$ ). 
ID4a - ID4b

There was a statistically significant difference between the indices of difficult $\left[\mathrm{F}(1.94)=4.62 ; p=.034 ; \mathrm{n}^{2}=0.05\right]$ and interaction between index of difficult and Groups $\left[\mathrm{F}(1.94)=6.85 ; p=.010 ; \mathrm{n}^{2}=0.07\right]$. This result demonstrates that the movement time increased significantly from ID4a $($ mean $=1449 \pm 60 \mathrm{~ms})$ to ID4b (mean $=1614 \pm 6 \mathrm{~ms})$. However, this increase was significant in the CP group from ID4a $($ mean $=1791 \pm 92 \mathrm{~ms}$ ) to ID4b (mean $=2157 \pm 154 \mathrm{~ms})$, while in the TD group the increase was not significant $($ mean $=1107 \pm 92 \mathrm{~ms}$ for mean $=1071 \pm 154 \mathrm{~ms}$, respectively).

The difference between groups remained $\left[\mathrm{F}(1.94)=29.7 ; p<.001 ; \mathrm{n}^{2}=0.24\right]$; the individuals of the $\mathrm{CP}$ group $($ mean $=1974 \pm 115 \mathrm{~ms}$ ) were $885 \mathrm{~ms}$ slower than the TD group $($ mean $=1089 \pm 115 \mathrm{~ms})$.

These findings suggest that this group with CP did not total obey the relation between size and distance of targets (see Fitts' law). This observation becomes evident when comparing the results of ID4a and ID4b, which should have presented the same difficulty. However, we found that movement time increased significantly from ID4a to ID4b in individuals with $\mathrm{CP}$, while in the TD group this difference did not occur, respectively). Interestingly, this result is controversial to our hypothesis that there would be no differences between ID4a and ID4b.

MANOVA was used to compare the slope of the regression line (Fig. 2) and there was no statistical difference between the groups in relation to the slope of the curve (b1) or between the dispersion of movement time $\left(r^{2}\right)$ data between the groups. However, the b0 (intercept), values presented statistically significant differences $[\mathrm{F}(1.95)=11.3 ; p=.001]$, with a greater movement time in the CP group $[$ mean $=1150 \pm 1100$ milliseconds (ms)] compared to the TD group (mean $=560 \pm 70 \mathrm{~ms})$.

Marginally significant inverse correlations were identified between the values of the slope of the curve and age and between the dispersion of movement time and GMFCS (Table 1) using the Pearson correlation, which did not occur with the MACS.

The linear regression analysis revealed a significant finding, $\mathrm{F}(6,41)=2.44, p=0.041, \mathrm{r} 2=0.263$, resulting in the following equation: increase in movement time $($ ID4a - ID2 $)=0.045 \times$ GMFCS. In other words, only the GMFCS influenced the increase in movement time, but age, gender and MACS did not contribute. To understand which factors influenced the increase in movement time from ID4a to ID4b, another regression analysis was performed between difference between ID4a and ID4b with age, gender, GMFCS and MACS, but there were no significant findings for the regression model.

\section{Discussion}

The majority of functional manual skills upper limb require fast and accurate performance which we observed was affected in individuals with Cerebral Palsy (CP), who demonstrated significantly greater movement time regardless of the task difficulty when compared with typically developed individuals. For individuals with $\mathrm{CP}$, a typical payoff between speed and accuracy was found, except importantly that they presented with more difficulty performing tasks involving smaller targets than when moving longer distances. Our findings are important as for the first time we can specifically evidence both therapy and device us in this group.

Considering this specific motor control difficulty, and the associated higher neuromuscular cost for individuals

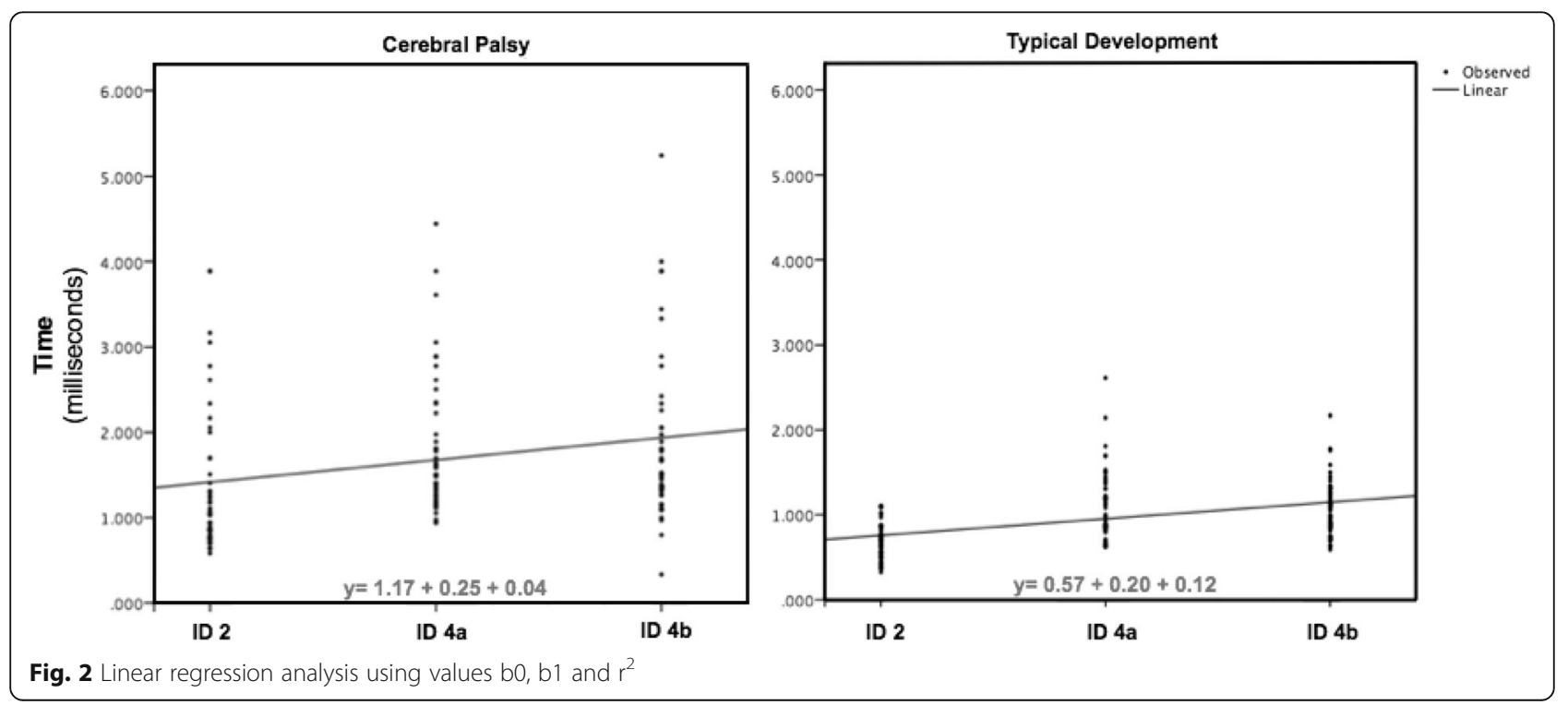


Table 1 Pearson's correlation between the values of b0, b1 and $r^{2}$, age, GMFCS and MACS

\begin{tabular}{|c|c|c|c|c|c|c|}
\hline \multirow[t]{2}{*}{ Variables } & \multicolumn{2}{|l|}{ Age } & \multicolumn{2}{|l|}{ GMFCS } & \multicolumn{2}{|l|}{ MACS } \\
\hline & $r$ & $p$ & $r$ & $p$ & $r$ & $p$ \\
\hline b0 & -0.035 & 0.737 & 0.022 & 0.880 & 0.151 & 0.306 \\
\hline b1 & -0.119 & $0.052^{*}$ & 0.216 & 0.141 & 0.129 & 0.384 \\
\hline$r^{2}$ & 0.083 & 0.421 & -0.280 & $0.054^{*}$ & -0.224 & 0.125 \\
\hline
\end{tabular}

GMFCS, Gross Motor Function Classification System; MACS, Manual Ability Classification System; * marginally statistically significant difference

with $\mathrm{CP}$, particularly those with more severe disability, we propose therapists should consider the difficulty performing dexterous tasks that involve fine control, and implement adaptations to increase target size in particular when aiming to reduce neuromuscular demand in occupational situations. Our findings inform therapeutic exercises and the design of a number of occupational tasks for example in the optimal design of communication computer switch systems.

In this study it was verified that the $\mathrm{CP}$ group used longer movement times to complete the tasks than did the typical developed (TD) group. An inverse relationship was observed between speed and accuracy of movement in individuals with TD but not in those with CP. These findings, as presented before, are contrary to our hypothesis and suggest that this group with $\mathrm{CP}$ did not obey the relation between size and distance of targets (see Fitts' law). This observation becomes evident when comparing the results of ID4a and ID4b, which should have presented the same difficulty. However, we found that movement time increased significantly from ID4a $($ mean $=1791 \pm 92 \mathrm{~ms})$ to ID4b (mean $=2157 \pm 154 \mathrm{~ms})$, in individuals with $\mathrm{CP}$, while in the TD group this difference did not occur (mean $=1107 \pm 92 \mathrm{~ms}$ for mean $=1071 \pm 154 \mathrm{~ms}$, respectively).

These results partially corroborate the findings of Smits-Elgesman [34], who affirmed that individuals with $\mathrm{CP}$ require more time to perform the task. The authors also reported that both $\mathrm{CP}$ and control groups responded similarly to increasing indices of difficulty, in agreement with the relation between speed and accuracy. This was only partially observed in our present study: in fact, based on our present findings, when observing results from ID2 compared with ID4 there is an influence between speed and accuracy. In ID2 both groups had a smaller movement time compared with ID4. However, considering ID4a versus ID4b individuals with CP had more problems with accuracy (narrow targets, ID4a) than speed (more distant targets, ID4b), this is probably due to weakness, altered reflexes and difficulties in body coordination, that lead to impaired postural control $[35,36]$.

Davies [4] also found evidence of individuals with CP not following the relation between speed and accuracy.
These authors stated that the International Organization for Standardization indicates that tasks requiring accuracy, such as a point-and-click task, present a low ID if less than 4 and a high ID if greater than 6 . However, the study of Davies [4] showed that the ID for individuals with bilateral CP should be limited to a maximum of ID2, which could also be associated with the different performance of $\mathrm{CP}$ individuals between the ID4a and ID4b found in this study.

Michmizos [31] reported that the analysis of movement time is an indicator of neurological integrity. In this context, delays in movement time have been seen in studies that evaluated individuals with CP $[37,38]$, in agreement with that shown in the present study, in which was noted that individuals with $\mathrm{CP}$ began to execute the task with a movement time greater $($ mean $=1150 \pm 1100 \mathrm{~ms})$ than the TD group (mean $=560 \pm 70 \mathrm{~ms}$ ).

Considering the slope of the curve (b1), the CP group did not differ from TD group in the present study, which demonstrates that the individuals with $\mathrm{CP}$ evolved during the attempts, similarly to those with TD, although the group with $\mathrm{CP}$ maintained greater movement time for all levels of difficulty compared to the TD. This can be confirmed by the analysis of the performance differences in the indices of difficulty, in which greater time of movement was observed from ID2 to ID4a for both groups.

Both groups did not differ also regarding dispersion of movement time $\left(r^{2}\right)$ in the evaluated groups; however, both groups presented $r^{2}$ values less than 1 , which means that there was variation in movement time values. Although, with no significance, the $\mathrm{CP}$ group presented greater variation during the execution of attempts than the TD, verified by a lower value of dispersion of movement time (see Fig. 2). These findings (i.e., the lower movement speed and larger dispersion of the data of the $\mathrm{CP}$ group), have also been reported in several studies [4, 34, 39-41], which further suggests a decline in the motor control system associated with impairments that affect both nervous and muscular structures. Furthermore, there is evidence from previous studies that movement time is much larger in individuals with CP than in those with TD [42-45].

The correlation analyses performed to investigate the association between the task measurements and MACS, GMFCS and age (made by Pearson coefficients) showed that there was no correlation between MACS and age, intercept, slope of the curve and movement time dispersion. This finding can be explained by the sample classification (levels I, II, III), as they were able to manipulate the mouse and adequately perform the task. This was also emphasized by Davies [46], who related that individuals with levels I, II and III are able to use a mouse to access a computer, thus the MACS was not sensitive to 
this relation. In addition, Eliasson [25], described that approximately $65 \%$ of individuals with $\mathrm{CP}$ are classified as levels I to III of MACS, a fact that confirms the levels used in this study.

On the other hand, there was a significant negative correlation between slope of the curve and age, movement time dispersion and GMFCS. These findings demonstrate that the higher the age of the individual, the less the slope of the curve, i.e. the less time this individual would need to perform the task (older individuals were less sensitive to increases in indices of difficult), and the higher the level of the GMFCS, the lower the value of movement time dispersion (i.e. higher the level of the GMFCS, greater the dispersion of the movement time data). As well as the regression analysis showed that the GMFCS influenced the increase in movement time from ID2 to ID4a, i.e., the higher the GMFCS, the greater the increase in movement time.

With respect to impairment in motor function, studies such as those by Haak [47] and Hanna [48], reported that there is a decline in motor function into adulthood in individuals with severe $\mathrm{CP}$, which can be explained by decreased activity, increased body size and changes in spinal alignment, therefore, it is believed that the better performance displayed by older individuals in the present study was due to higher levels of motor function, i.e. we did not evaluated severe levels, GMFCS V and MACS IV and V.

Thus, to improve the motor performance in individuals with $\mathrm{CP}$ which targets the performance of activities of daily living, it is necessary to construct and adapt rehabilitation therapies, including tasks that involve speed and accuracy demands [31]. Moreover, as with CP individuals had larger movement times for increased accuracy demands as compared to increased speed it is suggested that treatments should target accuracy demands, an element that is generally not considered by professionals during conventional therapy, which often emphasizes stretching and strengthening exercises.

\section{Limitations and future studies}

A limitation of this study is, that we were unable to explore the relationships of motor (spasticity and range of motion), visual or sensory functioning to speed and accuracy data; the impact of these variables should now be explored in an appropriately powered study. The variation of the topographic type, MACS and GMFCS levels can be considered vies in this study, however the sample represents the distribution of impairment in this population. In addition, we did not assess kinematic features of the movement to strength our results, as well as we did not evaluate more indices of difficulties, so we believe that further studies in CP should insert these evaluations as additional analysis considered alongside presenting symptoms.

\section{Conclusions}

Individuals with $\mathrm{CP}$ presented greater difficulty when the target was smaller and demanded more accuracy, and less difficulty when the task demanded speed. It is suggested that treatments should target accuracy demands, that could help in daily life tasks and is an element that is generally not considered by professionals during therapy.

Thus, therapists should be made aware of this difficulty performing tasks that involve fine control, and consider implementing adaptations to increase target size in particular when aiming to reduce neuromuscular demand in occupational situations, with appreciation the training of functional activities that address the motor control with focus on the evolution of accuracy of movement.

Our results advise the need to implement precision training in therapies and therefore the adaptation of computer systems to integrate considerations of distance and target accuracy in order to improve and ease engagement in occupational tasks.

\section{Abbreviations \\ b0: Intercept; b1: Slope of the curve; CP: Cerebral palsy; GMFCS: Gross motor function classification system; ID: Index of difficulty; ID2: Index of difficult 2; ID4a: Index of difficult 4a; ID4b: Index of difficult 4b; MACS: Manual ability classification system; $r^{2}$ : Dispersion of the movement time; TD: Typical development}

\section{Acknowledgements}

We thank the participants who provided their data for the study.

Funding

No funding.

Availability of data and materials

The dataset of the current study is available from the corresponding author on reasonable request.

\section{Authors' contributions}

DCGLF, MTAP and CBMM designed and coordinated the study. TDS performed the statistical analyses and interpreted the data. DCGLF, MTAP, TM and CBMM drafted the article and interpreted the data. DCGLF and MTAP collected the patient data. LCA, FHM and HD revised the manuscript critically for important intellectual content. All authors read and approved the final manuscript.

\section{Ethics approval and consent to participate}

This study was approved by the Research Ethics Committee of the ABC School of Medicine (Santo André, Brazil) under number 336.338 and CAEE: 14,652,713.9.0000.0082. All participants and/or their parents signed an informed consent form, and receive written and verbal information before participation of this study.

\section{Consent for publication \\ Not applicable.}

Competing interests

The authors declare that they do not have any competing interests. 


\section{Publisher's Note}

Springer Nature remains neutral with regard to jurisdictional claims in published maps and institutional affiliations.

\section{Author details \\ ${ }^{1}$ University of West Paulista, Presidente Prudente, SP, Brazil. ' Laboratory Design and Scientific Writing Department of Basic Sciences, ABC Faculty of Medicine, Av. Príncipe de Gales, 821, Vila Principe de Gales, Santo André, SP 09060-650, Brazil. 35chool of Arts, Sciences and Humanities, University of São Paulo, São Paulo, SP, Brazil. ${ }^{4}$ Post-graduate Program in Rehabilitation Sciences, Faculty of Medicine, University of São Paulo, São Paulo, SP, Brazil. ${ }^{5}$ Oxford Institute of Nursing and Allied Health Research, Oxford Brookes University, Oxford, UK. ${ }^{6}$ Department of Clinical Neurology, University of Oxford, Oxford, UK.}

Received: 27 December 2016 Accepted: 12 July 2017

Published online: 27 July 2017

\section{References}

1. Yeargin-Allsopp M, Van Naarden BK, Doernberg NS, Benedict RE, Kirby RS, Durkin MS. Prevalence of cerebral palsy in 8-year-old children in three areas of the United States in 2002: a multisite collaboration. Pediatrics. 2008; doi: 10.1542/peds.2007-1270.

2. Bax M, Goldstein M, Rosenbaum P, Leviton A, Paneth N. Proposed definition and classification of cerebral palsy. Dev Med Child Neurol. 2005;47:571-6.

3. Rosenbaum P, Paneth N, Leviton A. Goldstein M; Bax M. A report: the definition and classification of cerebral palsy April 2006. Dev Med Child Neurol 2007; 109:8-14.

4. Davies TC, Almanji A, Stott NS. A cross-sectional study examining computer task completion by adolescents with cerebral palsy across the manual ability classification system levels. Dev Med Child Neurol. 2014; doi:10.1111/dmcn.12521.

5. Thiel EV, Steenbergen B. Shoulder and hand displacements during hitting, reaching, and grasping movements in hemiparetic cerebral palsy. Mot Control. 2001:5:166-82

6. Law K, Lee EY, Fung BK, Yan LS, Gudushauri P, Wang KW, et al. Evaluation of deformity and hand function in cerebral palsy patients. J Orthop Surg Res. 2008; doi:10.1186/1749-799X-3-52.

7. Sorsdahl AB, Moe-Nilssen R, Kaale HK, Rieber J, Strand LI. Change in basic motor abilities, quality of movement and everyday activities following intensive, goal-directed, activity-focused physiotherapy in a group setting for children with cerebral palsy. BMC Pediatr. 2010; doi: 10.1186/1471-2431-10-26.

8. Park ES, Sim EG, Rha DW. Effect of upper limb deformities on gross motor and upper limb functions in children with spastic cerebral palsy. Res Dev Disabil. 2011; doi:10.1016/j.ridd.2011.07.021.

9. Arnould C, Penta M, Thonnard JL. Hand impairments and their relationship with manual ability in children with cerebral palsy. $J$ Rehabil Med. 2007;39:708-14.

10. Öhrvall AM, Eliasson AC, Löwing K, Ödman P, KrumlindeSundholm L. Selfcare and mobility skills in children with cerebral palsy, related to their manual ability and gross motor function classifications. Dev Med Child Neurol. 2010;52:1048-55.

11. Figueiredo PR, Silva PL, Avelar BS, da Fonseca ST, Bootsma RJ, Mancin MC. Upper limb performance and the structuring of joint movement in teenagers with cerebral palsy: the reciprocal role of task demands and action capabilities. Exp Brain Res. 2015;233(4):1155-64. doi:10.1007/ s00221-014-4195-3.

12. Ross SM, MacDonald M, Bigouette JP. Effects of strength training on mobility in adults with cerebral palsy: a systematic review. Disabil Health J. 2016; doi:10.1016/j.dhjo.2016.04.005

13. Moreau NG, Bodkin AW, Bjornson K, Hobbs A, Soileau M, Lahasky K. Effectiveness of rehabilitation interventions to improve gait speed in children with cerebral palsy: systematic review and meta-analysis. Phys Ther. 2016; doi:10.2522/ptj.20150401

14. Dewar R, Love S, Johnston LM. Exercise interventions improve postural control in children with cerebral palsy: a systematic review. Dev Med Child Neurol. 2015; doi:10.1111/dmcn.12660.

15. Novak I, Mclntyre S, Morgan C, Campbell L, Dark L, Morton N, Stumbles E, Wilson SA, Goldsmith S. A systematic review of interventions for children with cerebral palsy: state of the evidence. Dev Med Child Neurol. 2013; doi: 10.1111/dmcn.12246.

16. Missenard O, Fernandez L. Moving faster while preserving accuracy. Neuroscience. 2011; doi:10.1016/j.neuroscience.2011.09.020.

17. Gribble PL, Mullin LI, Cothros N, Mattar A. Role of Cocontraction in arm movement accuracy. J Neurophysiol. 2003; doi:10.1152/jn.01020.2002.

18. Popescu F, Hidler JM, Rymer WZ. Elbow impedance during goal-directed movements. Exp Brain Res. 2003;152:17-28.

19. Selen LP, Beek PJ, van Dieën JH. Impedance is modulated to meet accuracy demands during goal-directed arm movements. Exp Brain Res. 2006;172:129-38.

20. Selen LP, Franklin DW, Wolpert DM. Impedance control reduces instability that arises from motor noise. J Neurosci. 2009; doi:10.1523/ JNEUROSCI.2826-09.2009.

21. Wong J, Wilson ET, Malfait N, Gribble PL. Limb stiffness is modulated with spatial accuracy requirements during movement in the absence of destabilizing forces. J Neurophysiol. 2009; doi:10.1152/jn.91188.2008.

22. Imms C, Wallen M, Elliott C, Hoare B, Randall M, Greaves S, Adair B, Bradshaw E, Carter R, Orsini F, Shih ST, Reddihough D. Minimising impairment: protocol for multicentre randomised controlled trial of upper limborthoses for children with cerebral palsy. BMC Pediatr. 2016;16:70. doi: 10.1186/s12887-016-0608-8.

23. Meskers CGM, de Groot JH, de Vlugt E, Schouten AC. NeuroControl of movement: system identification approach for clinical benefit. Front Integr Neurosci. 2015; doi:10.3389/fnint.2015.00048

24. Palisano RJ, Cameron D, Rosenbaum PL, Walter SD, Russell D. Stability of the gross motor function classification system. Dev Med Child Neurol. 2006; doi: 10.1111/j.1469-8749.2006.tb01290.x.

25. Eliasson AC, Krumlinde Sundholm L, Rösblad B, Beckung E, Arner M Öhrvall AM, Rosenbaum P. The manual ability classification system (MACS) for children with cerebral palsy: scale development and evidence of validity and reliability. Dev Med Child Neurol. 2006; doi:10. 1111/j.1469-8749.2006.tb01313.x.

26. Morris C, Bartlett D. Gross motor function classification system: impact and utility. Dev Med Child Neurol. 2004;46(1):60-5.

27. Okazaki VHA. Discrete Aiming Task (v.2.0). 2007. http://okazaki.webs.com/ softwaresdownloads.htm\#297051518. Accessed 4 July 2011.

28. Ifft PJ, Lebedev MA, Nicolelis MAL. Cortical correlates of Fitts' law. Front Integr Neurosci. 2011; doi:10.3389/fnint.2011.00085.

29. Fitts PM. The information capacity of the human motor system in controlling the amplitude of movement. J Exp Psychol. 1954;47:381-91.

30. Schmidt RA, Zelaznik H, Hawkins B, Frank JS, Quinn JT. Motor-output variability: a theory for the accuracy of rapid motor acts. Psychol Rev. 1979:47(5):415-51.

31. Michmizos KP, Krebs HI. Reaction time in ankle movements: a diffusion model analysis. Exp Brain Res. 2014; doi:10.1007/s00221-014-4032-8.

32. Boyd LA, Vidoni ED, Siengsukon CF, Wessel BD. Manipulating time-toplan alters patterns of brain activation during the Fitts' task. Exp Brain Res. 2009;194:527-39.

33. Lam MY, Hodges NJ, Virji-Babul N, Latash ML. Evidence for slowing as a function of index of difficulty in young adults with down syndrome. Am J intellect Dev Disabil. 2009:114:411-26.

34. Smits-Engelsman BCM, Rameckers EAA, Duysens J. Children with congenital spastic hemiplegia obey Fitts' law in a visually guided tapping task. Exp Brain Res. 2007; doi:10.1007/s00221-006-0698-X.

35. Do JH, Yoo EY, Jung MY, Park HY. The effects of virtual reality-based bilateral arm training on hemiplegic children's upper limb motor skills. Neuro Rehabilitation. 2016; doi:10.3233/NRE-161302.

36. Seruya M, Johnson JD. Surgical treatment of pediatric upper limb spasticity: the shoulder. Semin Plast Surg. 2016; doi:10.1055/s-0035-1571253.

37. Horgan JS. Reaction-time and movement-time of children with cerebral palsy: under motivational reinforcement conditions. Am J Phys Med. 1980:59:22-9.

38. Chang JJ, Wu TI, Wu WL, Su FC. Kinematical measure for spastic reaching in children with cerebral palsy. Clin Biomech. 2005; doi:10. 1016/j.clinbiomech.2004.11.015.

39. Bravo PE, Legare M, Cook AM, Hussey S. A study of the application of Fitts' law to selected cerebral palsied adults. Percept Mot Skills. 1993;77:1107-17.

40. Legare M, Wolak C, Doyle B. Stimulus-response compatibility in a small sample of cerebral palsied adults. Percept Mot Skills. 1994;79:1459-74.

41. Gump A, Legare M, Hunt DL. Application of Fitts' law to individuals with cerebral palsy. Percept Mot Skills. 2002;94:883-95. 
42. Keates S, Hwang F, Langdon P, Clarkson PJ, Robinson P. Cursor measures for motion-impaired computer users. Proceedings of the fifth international ACM conference on assistive technologies. ACM: Edinburgh; 2002. doi:10.1145/638249.638274.

43. Hwang F, Keates S, Langdon P, Clarkson J. Mouse movements of motion-impaired users: a submovement analysis. J SIGACCESS Access Comput. 2003; doi:10.1145/1028630.1028649.

44. Hwang F, Keates S, Langdon P, Clarkson J. A submovement analysis of cursor trajectories. Behav Inf Technol. 2005; doi:10.1080/01449290412331327474.

45. Wobbrock JO, Fogarty J, Liu S, Kimuro S, Harada S. The angle mouse: targetagnostic dynamic gain adjustment based on angular deviation. Proceedings of the 27th international conference on human factors in computing systems; Boston, MA: ACM, 2009:1401-10.

46. Davies TC, Chau T, Fehlings DL, Ameratunga S, Stott NS. Youth with cerebral palsy with differing upper limb abilities: how do they access computers? Arch Phys Med Rehabil. 2010;91:1952-6.

47. Haak P, Lenski M, Hidecker MJC, Li M. Paneth N. Dev Med Child Neurol. 2009; doi:10.1111/j.1469-8749.2009.03428.x

48. Hanna SE, Rosenbaum PL, Bartlett DJ, Palisano RJ, Walter SD, Avery L, Russell DJ. Stability and decline in gross motor function among children and youth with cerebral palsy aged 2 to 21 years. Dev Med Child Neurol. 2009:51(4):295-302.

Submit your next manuscript to BioMed Central and we will help you at every step:

- We accept pre-submission inquiries

- Our selector tool helps you to find the most relevant journal

- We provide round the clock customer support

- Convenient online submission

- Thorough peer review

- Inclusion in PubMed and all major indexing services

- Maximum visibility for your research

Submit your manuscript at www.biomedcentral.com/submit
C Biomed Central 